\title{
Enoturismo no Brasil: um estudo comparativo dos perfís dos enoturistas do Vale dos Vinhedos e do Vale de São Francisco
}

\author{
Bárbara Dal Rosso Lima \\ Universidade do Minho - Braga - Portugal \\ J. Cadima Ribeiro \\ Universidade do Minho - Braga - Portugal \\ ORCID: https://orcid.org/0000-0002-4434-0766 \\ Vinícius Pinheiro Nunes \\ Universidade Federal de Rio Grande - Porto Alegre - RS - Brasil
}

\section{Resumo}

O enoturismo tem apresentado importância crescente, mostrando-se como alternativa de desenvolvimento para as regiões vitivinícolas. Entretanto, a literatura aponta a existência de uma lacuna de informação sobre as caraterísticas e comportamentos dos visitantes. Em razão disso, o presente estudo tem como objetivo principal determinar o perfil dos visitantes da regiões vitivinícolas brasileiras do Vale dos Vinhedos e do vale de São Francisco. Recorreu-se a dados qualitativos e quantitativos sobre os enoturistas. Os inquéritos foram aplicados aos turistas que visitaram essas regiões vinícolas e os dados foram submetidos a técnicas estatísticas multivariadas com o objetivo de segmentar os visitantes. Os resultados apontam que as visitas podem ter diferentes motivações. Percebeu-se, também, que os turistas encontrados no Vale dos Vinhedos e no Vale de São Francisco têm perfis distintos. Em matéria de estratificação, obtiveram-se quatro segmentos: apaixonados; interessados; visitantes ocasionais; e indiferentes. Os resultados da investigação sugerem que conhecer melhor o perfil do enoturista possibilita a implementação de novas estratégias de marketing e ajuda a formatar a oferta.

Palavras-chave: Enoturismo. Perfil dos enoturistas. Motivações de visita. Vale dos Vinhedos. Vale de São Francisco.

Wine Tourism in Brazil: a comparative research on the profile of the wine tourists of Vale dos Vinhedos and Vale de São Francisco

Abstract

Wine tourism has become increasingly important to the development of the vineyard regions. However, the literature points out that there is a lack of information regarding the visitors ' behavior and profile. This keeping in mind, the present research aims to determine the tourists' profile of the Brazilian wine regions of Vale dos Vinhedos and Vale de São Francisco. A research tool was developed to obtain qualitative and quantitative data about wine tourists. The surveys were applied to the tourists who visited these regions. The data 
were submitted to multivariate statistical techniques with the objective of obtaining different wine tourists segments. Different wine tourists' profiles were found on the two wine regions. In what regards the segmentation of the visitors, four segments of wine tourists were obtained: the passionate; the interested; the occasional visitors; and the indifferent. The empirical results attained also suggest that knowing the profile of the wine tourist better will enable the implementation of new marketing strategies and the improvement of the supply.

Keywords: Wine tourism. Wine tourists profile. Visitors motivation. Vale dos Vinhedos. Vale de São Francisco.

\section{Enoturismo en Brasil: un estudio comparativo de los perfiles de los enoturistas del Valle de los Viñedos y del Valle de San Francisco}

\section{Resumen}

El enoturismo ha presentado una importancia creciente, mostrándose como alternativa de desarrollo para las regiones vitivinícolas. Sin embargo, la literatura apunta la existencia de una laguna de información sobre las características y comportamientos de los visitantes. En consecuencia, el presente estudio tiene como objetivo principal determinar el perfil de los visitantes de las regiones vitivinícolas brasileñas del Valle de los Viñedos y del Valle de San Francisco. Se recurrió a datos cualitativos y cuantitativos sobre los enoturistas. Las encuestas se aplicaron a los turistas que visitaron esas regiones vinícolas y los datos se sometieron a técnicas estadísticas multivariadas con el objetivo de segmentar a los visitantes. Los resultados apuntan que las visitas pueden tener diferentes motivaciones. Se percibió, también, que los turistas de vino encontrados en el Valle de los Viñedos y en el Valle de San Francisco tienen perfiles distintos. En materia de estratificación, se obtuvieron cuatro segmentos: apasionados; interesados; visitantes ocasionales; e indiferentes. Los resultados de la investigación sugieren que conocer mejor el perfil del enoturista posibilita la implementación de nuevas estrategias de marketing y ayuda a dar formato a la oferta.

Palabras clave: Enoturismo. Perfil de los enoturistas. Motivos de visita. Valle de los Viñedos. Valle de San Francisco.

\section{Introdução}

Nas suas diferentes manifestações, o turismo tem-se mostrado como possível fonte de desenvolvimento social, econômico e ambiental, embora, muitas vezes, seja uma atividade econômica subestimada, ao não considerar-se o efeito multiplicador que tem noutras atividades industriais e econômicas, em geral (Taylor 2006).

Sendo uma prática relativamente nova, o enoturismo surge como um caminho para dar dinamismo ao espaço rural, configurando um tipo de turismo emergente na contemporaneidade (Inácio 2008), além de gerar sustentabilidade, receita e ser uma oportunidade para diversificar a economia das regiões vitivinicultoras (O'Neil e Charters 2000).

A palavra enoturismo surgiu da ligação do termo eno, de origem grega, derivada da palavra ôinos (vinho), com a palavra turismo (Locks e Tonini 2005). Por se tratar de um segmento complexo, que contempla caraterísticas semelhantes às de outros tipos de turismo, não é um fenômeno de fácil conceituação (Getz 1998).

As pesquisas realizadas sobre esta temática têm crescido significativamente nos últimos anos, muito embora boa parte delas tenha sido realizada na ótica da 
oferta, privilegiando as informações obtidas através dos produtores, enólogos e proprietários de empreendimentos vitivinícolas.

Acredita-se que compreender quais são as caraterísticas destes visitantes, sejam elas sociodemográficas, socioeconômicas, relacionadas com a motivação, interesse e conhecimento do setor ou ainda percepções sobre a experiência, seja de suma importância no intento de compreender melhor o fenômeno e derivar daí políticas públicas e estrastégias de negócio.

A literatura existente mostra que existe uma lacuna a ser preenchida, dado que pouco se sabe sobre o enoturista, em especial no que se refere às suas caraterísticas psicológicas, motivações e preferências (Charters e Ali-Knight 2002). Desta forma, é necessário que se possa traçar um perfil para que seja possível compreender melhor o fenómeno, como um todo (Mitchell, Hall e Mcintosh 2002).

As caraterísticas destes visitantes podem sofrer variações, conforme a origem e local de pesquisa. Isto faz com que a realização de novas investigações sob este tema em outras partes do mundo seja ainda mais importante (Charters e AliKnight 2002). Além disso, os grupos de turistas são cada vez mais diversos e heterogêneos. Por isso, a segmentação auxilia a conhecer o mercado, agrupando os consumidores pelas suas semelhanças e utilizando como critérios suas necessidades, atributos e comportamentos (Peter e Olson 2001).

No cenário brasileiro, à medida que a vitivinicultura nacional foi crescendo em qualidade, o enoturismo começou a multiplicar-se e já se regista um fluxo considerável em múltiplas localidades produtoras de vinho. No Vale do Vinhedos, em concreto, o enoturismo representa já uma parcela bastante significativa da faturação (Valduga 2012).

Este estudo propõe-se a realização de uma análise das caraterísticas dos visitantes das regiões vitivinícolas brasileiras do Vale do São Francisco (VSF) e do Vale dos Vinhedos ( $\mathrm{V}$ ), mais precisamente daqueles que se dirigem às empresas vitivinícolas destes locais, através da aplicação de questionários, entrevistas e revisão bibliográfica. Almeja-se traçar o perfil destes enoturistas e, posteriormente, segmentá-los, realizando um estudo na ótica da procura que seja capaz de trazer mais informações sobre o consumidor do setor do turismo de vinhos.

Como pergunta de pesquisa, tomou-se a seguinte: Como se caraterizam os visitantes das empresas vinícolas localizadas no Vale do São Francisco e no Vale dos Vinhedos?

Identificado que está o objeto e os objetivos do presente estudo, faz-se necessário mencionar como se estrutura o texto. Sucedendo à Introdução, temos a revisão da literatura sobre a temática do enoturismo e do enoturista. Seguem-se a referência aos métodos de investigação usados e uma breve caraterização dos territórios objeto de estudo. Logo após temos a análise dos dados empíricos, incluíndo a discussão dos resultados obtidos. A finalizar, encontram-se a conclusão e breves considerações de política. 


\section{Quadro conceitual: do enoturismo ao perfil do enoturista}

Para analisar o turismo é necessário levar em consideração as diferentes formas como se manifesta, compreender sua essência holística e avaliar uma grande diversidade de terminologias e critérios, muitas vezes complementares (Beni 2004; Panosso 2005).

Quanto ao enoturismo, Getz (2000) afirma que este é um sistema constituído por três elementos centrais: consumidor (turista); destino; e oferta. $\mathrm{O}$ turista é o ponto-chave tanto para a oferta quanto para a procura. Portanto, para compreender este fenômeno é preciso apreender o que o turista procura. Só então se pode ser capaz de oferecer um produto mais adequado às suas expectativas e necessidades.

No ano de 1998, ocorreu na Austrália a primeira conferência sobre enoturismo de que se tem notícia. A partir daí muitos artigos e estudos sobre o tema começaram a ser desenvolvidos. Inicialmente, o termo relacionava-se apenas com a visita a empresas vitivinícolas e caves para comprar e degustar vinhos, tendose transformado com o tempo em algo mais abrangente e complexo.

Pesquisadores das mais diversas partes do mundo têm realizado longos estudos com o intento de definir com mais clareza o que é enoturismo. Para Vargas et al. (2008), as abordagens podem levar em consideração três enfoques distintos: voltar-se para o turista; para as agências de turismo; ou para o produtor.

Hall et al. (2002), considerados autores clássicos desta temática, definem enoturismo como sendo visitas a vinhas, a empresas vinícolas, a participação em festivais do vinho ou em mostras de uvas em que a principal motivação dos turistas se prende com a degustação de vinhos e os atributos associados a uma região vitivinícola. Entretanto, Johnson (1998) afirma que relacionar a motivação apenas com o vinho é restringir demasiado o conceito, já que a visita a estas regiões pode não estar diretamente relacionada com o consumo de vinho mas sim com a paisagem e o contacto com a natureza.

Outros estudiosos, como Alant e Bruwer (2004), defendem, também, que os motivos da visita a uma região vitivinícola podem ser os mais diversos, seja comprar vinho, conhecer o lugar de produção de um rótulo específico ou buscar lazer e recreação.

Costa e Kastenholz (2009) afirmam que, de uma maneira geral, o enoturismo é um tipo de turismo que se localiza fora da zona urbana e que fomenta a divulgação das zonas vitivinícolas, aproveitando-se dos serviços turísticos, do patrimônio cultural e da paisagem aí existente. A ATOUT France (2010) entende que o enoturismo é uma forma de agregar valor para os produtores e profissionais da área, não apenas pela oportunidade de vender os seus produtos mas também pelo consumo de outros produtos e serviços oferecidos pelo destino.

Estes debates trazem à tona questionamentos importantes, como os limites existentes entre o enoturismo e outros tipos de turismo. Portanto, há muito espaço para investigar como as indústrias do vinho e do turismo podem aproveitar-se uma da outra e agregar valor à região onde estão inseridas (Cambourne et al. 2002).

Para o turismo enológico, os recursos naturais se manifestam através da paisagem, dos rios e montanhas, dos locais de cultivo das videiras, e são complementados por atrativos artificiais, do tipo cultural, como a produção do 
vinho, seus processos e as maquinarias utilizadas, o papel do vinho na história do povo, as festas para celebrar a colheita e seus frutos, a arquitetura das empresas vinícolas e a gastronomia típica comumente associada ao vinho (Zanini e Rocha 2010).

De acordo com Getz e Brown (2006), o principais predicados das regiões vitivinícolas são as expressões culturais, a atratividade do destino e os produtos do vinho. Mais consideram (Getz e Brown 2006) que existe uma relação entre os atrativos turísticos e o desenvolvimento das regiões produtoras.

A Associação Internacional do Enoturismo (AENOTUR, 2018) afirma, ainda, que o vinho, como produto turístico, faz parte da história, da arte, do folclore e da gastronomia, e chega ao mercado como um bem que faz parte da cultura de um determinado povo, trabalhando com todos os sentidos de perceção dos consumidores. Mancino e Lo Presti (2012) referem que o vinho pode permitir que os turistas encontrem instigação emocional para desvendarem a história e as tradições do território e experimentarem a sua atmosfera singular.

A opção pelo destino e a decisão de viajar são um processo complexo, influenciado pela motivação e por outros aspetos individuais. Acredita-se que o turista possua crenças prévias a respeito da experiência enoturística, uma expectativa que pode basear-se numa experiência anterior, na divulgação do local, ou mesmo em informações de terceiros (Hall et al. 2002). É importante salientar que quando um indivíduo adquire um serviço, é possível que as mãos saiam vazias mas a cabeça não. Esta sai cheia de informações que podem ser, e possivelmente serão, compartilhadas com outras pessoas (Lewis e Chambres 1989).

Boa parte dos estudos analisam os enoturistas e as suas relações com os serviços ou os produtos do vinho, e não averiguam os turistas do vinho, em geral (Williams e Kelly 2001), não havendo, em razão disso, um juízo unânime sobre o que são os enoturistas. Getz e Brown (2006) imputam este desacordo, em parte, à ausência de ou parcialidade na definição de outros conceitos, comos o de produto e de experiência enoturística.

Conhecer estas caraterísticas é um princípio básico para realizar um planeamento público-privado regional para atrair visitantes a uma determinada região. Entretanto, os autores que se têm preocupado com esta temática são categóricos na afirmação de que os turistas de vinho não são um grupo homogêneo (Charters e Ali-Knight 2002; Hall et al. 2002).

Diferentemente de Sparks (2007), que refere a ausência de um perfil para o enoturista, Reyes (2012) reclama a existência um grupo de caraterísticas de que os enoturistas costumam ser possuidores; são elas: busca de autenticidade; altos níveis de educação; grande interesse pelo turismo rural; desejo de calma e tranquilidade; atração pela gastronomia da região; e ligação entre a saúde e as atividades ao ar livre.

É válido lembrar que as primeiras menções aos enoturistas não propõem definições muito lisonjeiras. Spawton (1986) é um exemplo disso, ao descrevê-los como bêbados ambulantes (moblie drunks). Mckinna (1987), por seu turno, defendeu que os enoturistas consideram a visita que fazem apenas como "um bom feriado".

Conforme mencionado anteriormente, o enoturismo é muitas vezes entendido como parte do turismo rural, dado que não apenas o vinho mas também 
a paisagem motivam a deslocação (Novais e Antunes 2009). Neste sentido, Serrenho e Águas (2006) aceitam como enoturistas aqueles visitantes que se deslocam as regiões vitivinícolas e não estão fundamentalmente motivados pelo vinho, mas podem, por exemplo, desejar conhecer a arquitetura ou disfrutar da natureza. Entretanto, ficam de lado outras atividades que não ocorram no meio rural, como feiras e eventos que ocorrem nas cidades.

Reportando-se a Itália, Gatti e Maroni (2004) reclamam que o enoturista é usualmente do sexo masculino, de pouca idade e proveniente do estrangeiro. Lopez-Guzmán et al. (2008), ao analisarem os turistas de vinho no sul de Espanha, afirmam que são maioritariamente indivíduos com mais de cinquenta anos, com boas condições de vida e que viajam acompanhados pela família. Treloar, Hall e Mitchell (2004) sustentam que o enoturista que visita a Austrália é predominantemente mulher, estudante de graduação ou graduado, possui rendimento um pouco acima da média e algum conhecimento sobre vinho.

Mitchell, Hall e Mcintosh (2002) entendem que os enoturistas são pessoas de ambos os sexos, que possuem entre 30 e 50 anos de idade, vivem próximo da região que visitam, ganham salários acima da média, consomem vinho com frequência e possuem um conhecimento intermédio sobre o tema.

Aparte as diferenças anotadas, o perfil que emerge pode, igualmente, ser considerado simplista. Charters e Ali-Knight (2002) citam duas categorias existentes, na perspectiva do produtor: os bebedores sofisticados (sophisticated drinkers); e os consumidores ocasionais (casual tourists), sendo estes visitantes curiosos por novos conhecimentos, que olham e provam ou que não possuem conhecimento sobre o vinho, mas que consomem e querem aprender.

Boa parte dos investigadores da área costuma avaliar e identificar os grupos de enoturistas através de dois procedimentos distintos: um primeiro, baseado nas informações demográficas, sobre idade, gênero, origem, educação e família; e, outro, estabelecendo um perfil mais minucioso, focado no aspeto psicográfico, como as motivações, opiniões, áreas de interesse, crenças, valores e estilo de vida (Charters e Ali-Knight 2002; Mitchell e Hall 2006).

É importante salientar que o aspeto cultural deve ser levado em consideração, haja em vista que existem diferenças fundamentais entre a indústria do vinho localizada nos velho e no novo mundo. Desta forma, também é possível que os enoturistas apresentem perfis diferentes quando se compara uma e outra regiões continentais. Esta posição é ratificada por Charters e Ali-Knight (2002) ao identificarem variações entre os turistas nas regiões da Austrália.

A classificação dos enoturistas em grupos semelhantes, através da segmentação, tem-se mostrado essencial para compreender quais são as principais motivações dos visitantes e o que estes consideram importante durante a visita às empresas vitivinícolas. Além disso, para os operadores de enoturismo, a segmentação de mercado é necessária para auxiliar no desenvolvimento de produtos e inciativas de marketing (Mitchell, Hall e Mcintosh 2002; Williams e Kelly 2001).

Amiúde, as segmentações propostas têm por base informações sociodemográficas. No entanto, visitantes que apresentem caraterísticas demográficas parecidas podem apresentar divergências relevantes com relação aos aspetos psicográficos (Bruwer, Li e Reid 2002). Getz e Brown (2006) relembram, 
ainda, que o comportamento dos visitantes é influenciado por uma grande diversidade de variáveis, como o gênero, origem, estilo de vida, personalidade, experiência, motivaçõos e necessidades. Em expressão disso, os ditos autores (Getz e Brown 2006) propuseram a subdivisão das motivações dos enoturistas em quatro grandes grupos: as intelectuais, ligadas a aprendizagem e ao descobrimento e exploração do novo; as sociais, que se prendem com o desenvolvimento de relacionamentos interpessoais; as motivadas por propósitos de alteração de competências, relacionadas com o desejo de atingir algum objetivo específico ou concluir um desafio; e, por fim, as informadas pela vontade de fuga ao excesso de estímulos, com expressão no desejo de evasão.

Ao considerar como critério o nível de interesse dos visitantes pelo vinho, Johnson (1998) propôs uma das primeiras classificações, dividindo os enoturistas em especialistas, interessados no vinho e nas atividades com ele relacionadas, e os enoturistas, em geral, que estavam em busca de lazer e descanso.

Já Hall e Macionis (1998), levando em consideração o nível de conhecimento e interesse em relação ao vinho, propuseram uma divisão dos enoturistas em três categorias: apaixonados (wine lover); interessados (wine interested); e curiosos (wine curious).

Charters e Ali-Knight (2002), entre vários outros autores (por exemplo: Cambourne e Mancionis 2002; Brown, Havitz e Getz 2006; Marzo-Navarro e PedrajaIglesias 2009; ATOUT France 2010), propuseram igualmente uma classificação dos enoturistas, neste caso, partindo de uma auto-classificação destes, de que resultaram os seguintes grupos: apaixonados (wine lovers); conhecedores (the conosseur); interessados (wine interested); e iniados (wine novice).

Entre as proposta mais recentes, está a de Alebaki e lakovidou (2010), resultante de um estudo feito na Grécia, valendo-se especialmente dos aspetos sociodemográficos e das motivações dos turistas. Daí resultaram quatro grupos: os apaixonados (wine lovers) - os respondentes deste grupo consideram-se interessados ou altamente interessados no vinho e consomem-no com frequência; os neófitos (neophytes) - para este grupo a empresa vitivinícola, como atração, é um motivo importante para visitar a região; os visitantes ocasionais (occasional visitors) - que são motivados a visitar a região do vinho principalmente por causa da gastronomia local e uma boa parte deles não está interessada em desenvolver conhecimentos na área do vinho e da sua produção; e os acidentais (hangers-on) aqueles que vão à empresa vinícola sem interesse aparente no vinho, como parte de um grupo que decidiu visitar a atração.

No que se refere ao Brasil, por se tratar de um destino enoturístico relativamente recente, a informação referente aos turistas de vinho é ainda mais escassa. Faz-se então necessário o desenvolvimento de investigação que possibilite um melhor conhecimento do perfil do enoturista, e que, a partir daí, se possa desenvolver estratégias de marketing adequadas aos anseios e exigências de segmentos específicos de potenciais visitantes. 


\section{Metodologia}

A realização deste estudo envolveu percorrer três fases distintas: i) a revisão da literatura; ii) a realização de entrevistas; e iii) a aplicação de um questionário.

Feito o levantamento da literatura sobre a temática, a etapa seguinte da pesquisa teve um caráter qualitativo, valendo-se de entrevistas com personagens inseridos no contexto da atividade, para permitir maior aproximação à realidade. Num momento posterior desenvolveu-se um questionário para a obtenção de dados sobre o enoturista, seus hábitos, comportamentos, preferências e motivações. Essa etapa teve como objetivo não somente caracterizar e segmentar os visitantes das duas regiões vitivinícolas mas, também, compará-los.

A recolha de informações através de questionário estruturado, sobretudo com questões fechadas, visou a obtenção de dados de forma organizada, precisa e pouco dispendiosa sobre um conjunto relativamente alargado de indivíduos.

A opção por um questionário se dá por diversos fatores, como garantir o anonimato dos respondentes, obter informações sobre o tema de pesquisa, permitir que os inquiridos possam mencionar comportamentos, percepções e atitudes, além de evitar que as perguntas sejam apresentadas de forma distinta entre os inquiridos (Tassiopoulos, Nuntsu e Haydam 2004).

O cabeçalho do questionário tinha como objetivo identificar em qual região e empresa vinícola o enoturista estava inserido. Já o rodapé fornecia informações a respeito da pesquisa e da instituição de ensino e investigação no quadro da qual o estudo era realizado. Para facilitar o processo analítico, o questionário foi dividido em blocos, cuja estrutura se apresenta de seguida:

i) Bloco A - o primeiro grupo de questões tinha o intuito de obtenção de informação sobre as fontes de informação utilizadas pelos visitantes na escolha do local de visita, se pernoitaram, o tempo de estadia e o tipo de alojamento utilizado, além de outros aspetos comportamentais;

ii) Bloco B - o segundo bloco de questões reportava-se aos hábitos de consumo, conhecimento e interesse por vinhos, participação em confrarias e associações de vinho;

iii) Bloco C - o terceiro grupo de questões endereçava as questões da motivação tanto em relação ao vinho, propriamente dito, como aos atributos da região e à experiência turística visada;

iv) Bloco D - o objetivo deste bloco era identificar o valor gasto pelos turistas em produtos durante a visita;

v) Bloco E - esta parte do questionário almejava recolher informações sobre a satisfação do enoturista e a intenção de recomendar a visita a outras pessoas; e

vi) Bloco $\mathrm{F}$ - o grupo final de questões ligava-se aos aspetos socioeconómicos e demográficos, como gênero, idade e nível de escolaridade; procurou-se também identificar a proveniência geográfica, profissão, rendimento e estado civil do visitante. 
Os questionários foram administrados com 0 apoio das empresas vitivinícolas aderentes e aplicados entre os meses de dezembro de 2017 e fevereiro de 2018. O tipo de amostragem considerado foi o probabilístico, o qual foi realizado de forma sistemática, de modo a preencher o número de questionários necessários, e estratificado no que se refere às empresas pertencentes a cada vale. $O$ nível de confiança considerado no cálculo do tamanho amostral foi de $90 \%$ e a margem de erro de $4 \%$.

O tamanho da amostra mínima necessária para o Vale dos Vinhedos (VV) foi de 360 questionários e para o Vale de São Francisco (VSF) foi de 280 questionários. Porém, optou-se por coletar $15 \%$ a mais que os tamanhos amostrais mínimos, possibilitando assim invalidar questionários que não apresentassem todas as perguntas respondidas. Foram considerados válidos para análise 668 questionários, 360 desses provenientes do VV e 308 do VSF.

As respostas aos questionários foram analisadas considerando três etapas principais: i) na primeira etapa, realizou-se uma análise descritiva dos dados, a fim de identificar o perfil geral dos enoturistas quanto às variáveis relacionadas com informações socioeconômicas, fontes de informação, consumo, interesse e conhecimento sobre vinhos, motivação para a realização da visita e nível de satisfação; ii) de seguida, realizou-se o teste do Qui-Quadrado de independência, a fim de verificar a associação entre variáveis e cada um dos blocos, considerando um nível de significância de $5 \%$ - essas associações foram descritas em tabelas de contingência, contendo os valores absolutos e as respetivas percentagens, bem como a probabilidade (p), obtida; iii) na terceira etapa, optou-se por uma Análise de Correspondência Múltipla (ACM) para cada um dos blocos de questões, considerando-se apenas as variáveis que apresentaram associação significativa, ao nível de 5\%; aqui, utilizou-se o método de normalização simétrica e reduziu-se o relacionamento multivariado entre as variáveis a duas dimensões, possibilitando assim a apresentação de gráficos de correspondência para as regiões analisadas.

A ACM é um tipo de análise multivariada que foi utilizada com o intuito de formar grupos ou "clusters" a partir da relação entre as múltiplas variáveis, baseando-se nas distâncias ou proximidades entre categorias. Por meio dessa análise, foi possível identificar perfis caraterísticos de grupos específicos de enoturistas dos VV e VSF para cada um dos blocos de questões considerados e, a partir disso, atribuir classificações a esses grupos.

Todas as análises estatísticas foram realizadas por meio do software $R$ core Team (2017) e do software SPSS statistics 24, edição para estudantes.

\section{Breve apresentação dos territórios objeto de estudo}

Pode afirmar-se que os primórdios da vitivinicultura no Brasil se ligam ao processo de colonização portuguesa, iniciada na região nordeste do país. A partir daí, a história dos vinhos brasileiros se ampliou, especialmente no final do século XIX, com a chegada de imigrantes europeus de origens diversas. Eles se estabeleceram no sul, e na bagagem trouxeram suas técnicas de cultivo e seus hábitos de consumo regular de vinho. 
Far-se-á de seguida uma apresentação do desenvolvmento das práticas vitivinocolas no Vale dos Vinhedos e no Vale do São Francisco, regiões que estão intimamente ligadas à história da produção de uva e fabricação de vinho no Brasil. No mapa abaixo situam-se estas duas regiões vínicolas no quadro do território do Brasil (Figura 1).

Figura 1 - Localização do Vale dos Vinhedos e do Vale de São Francisco

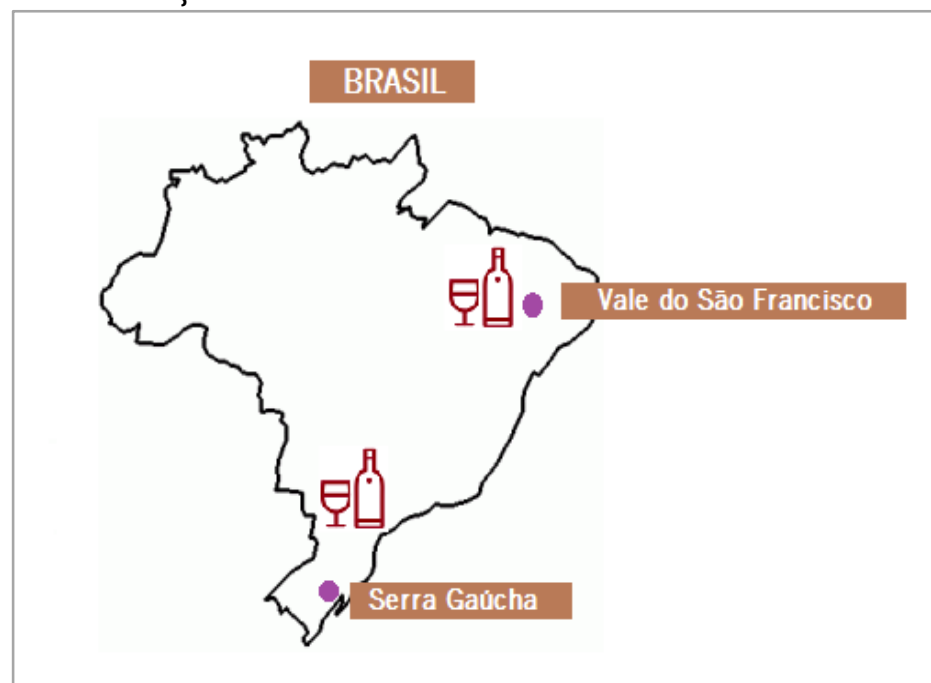

Fonte: Elaboração própria.

\subsection{O Vale dos Vinhedos}

O Vale dos Vinhedos se localiza no Estado do Rio Grande do Sul, mais precisamente, na Serra Gaúcha. A ocupação do local se deu através da imigração italiana, na segunda metade do Século XIX, a partir do ano de 1875, com famílias de Trento e de Venêto (Valduga 2012).

Inicialmente, o vinho, como todos os outros produtos, eram pouco aperfeiçoados e produzidos apenas para o próprio consumo e para o pequeno comércio local. Porém, aos poucos, a diversidade de atividades e produtos gerou relativa autossuficiência e o excedente passou a ser comercializado nas grandes cidades.

A implantação da ligação ferroviária com a capital favoreceu o comércio e a abertura de iniciativas de indústria e comércio, entre elas adegas e empresas vitivinícolas. Para Frizzo (1984), o encurtamento da distância pela ferrovia e a instalação da energia elétrica, em 1913, possibilitou a criação de condições básicas para a expansão e surgimento de novas atividades econômicas.

A partir das décadas de 20 e 30 começam a emergir diferenças internas entre as antigas colônias: Caxias do Sul se destaca na indústria de transformação, enquanto que Bento Gonçalves e Garibaldi ampliam seu investimento na agroindústria, especialmente vinícola (Falcade \& Mandelli, 1999; Valduga 2012). Ainda que hoje a significância dos ganhos do setor vitivinícola seja um pouco menor, pode dizer-se que a partir dos anos 50 esta atividade auxiliou no desenvolvimento da indústria moderna, sendo responsável por boa parte da acumulação de capital (Dancal e Gonzaga 1979). 
Atualmente, a região conta com múltiplas empresas vinícolas, sendo que 23 delas fazem parte da Associação de Produtores de Vinhos Finos do Vale dos Vinhedos - APROVALE. De acordo com sua página oficial na Internet (http://www.valedosvinhedos.com.br/), a APROVALE foi fundada em fevereiro de 1995, no intuito de promover o desenvolvimento do VV através do turismo enológico, visando integrar os associados e a comunidade, para oferecer produtos e serviços de excelência. Cabe-lhe, também, a responsabilidade de realizar o controlo de qualidade dos vinhos com Indicação Geográfica do Vale dos Vinhedos, bem como oferecer informações sobre o território, e alavancar o turismo.

Apesar da história vitivinícola da região estar intimamente ligada com a agricultura familiar, hoje existem não somente empresas familiares mas também grupos com participação internacional, que têm atendimento ao público durante todo o ano.

Atividades festivas durante a colheita da uva, cursos de degustação, jantares harmonizados, concursos nacionais e internacionais de vinhos, festivais enogastronômicos, eventos desportivos, encontros culturais e apresentações artísticas compõem uma programação diversificada (APROVALE 2018).

\subsection{O Vale de São Francisco}

Embora existam registos de cultivo de videiras nos estados da Bahia e Pernambuco já no século XVI, por ocasião do processo de colonização europeia, o

desenvolvimento da viticultura no Vale do São Francisco inicia-se, segundo Falcade (2005), a partir da década de 60, com a abertura de multinacionais do setor de bebidas, e também em razão dos investimentos gevernamentais em projetos que apoiavam a introdução da agricultura irrigada na região do semiárido no nordeste brasileiro.

As 3.000 horas de luz solar, recorrentes em quase todos os dias do ano, e a baixa precipitação pluviométrica, fazem da região um fênomeno intrigante para o mundo dos vinhos, conforme salientam Flores e Flores (2012):

A região responde por $90 \%$ das exportações de manga e uva de mesa, e já possui certificação de Indicação Geográfica. Também conta com sete vitivinícolas fabricantes de vinhos finos e vem ganhando destaque como produtora de espumantes e vinho.

As vinícolas de maior porte se distribuem pelos munícios de Lagoa Grande e Santa Maria da Boa Vista (Pernambuco) e Casa Nova (Bahia), mas estas cidades não dispõem de estruturas de suporte à atividade turística. Isto faz com que Petrolina concentre as opções hospedagem e gastronomia (Flores e Flores 2012).

$O$ desenvolvimento do enoturismo tem-se mostrado essencial para dar dinamismo ao VSF. De acordo com Galvão (2009), o enoturismo no VSF, além de auxiliar no crescimento econômico do local, faz com que os visitantes possam conhecer outros atrativos culturais, naturais e históricos, permitindo um contato entre o turista, a população e os aspetos tradicionais da região. 
A parceria público/privada que deu origem ao "Vapor do Vinho", atualmente "Vapor São Francisco", é algo que exalta esses atrativos. O passeio de barco pelo Rio São Francisco sai de Petrolina, passa pela eclusa, permite que os visitantes conheçam a Fazenda de Frutas, e finaliza na Ouro Verde, onde os turistas fazem uma visita guiada pela empresa vitivinícola e participam numa sessão de degustação. A atividade também inclui almoço com comida típica e música ao vivo.

A imagem da viticultura do VSF está intimamente ligada à tecnologia, à irrigação, a uma produção atípica, já que a paisagem do sertão nordestino difere totalmente daquela encontrada em outras regiões vínicas do mundo.

\section{Estudo Empírico}

As seções a seguir têm como objetivo apresentar os resultados empíricos, em conformidade com os objetivos de pesquisa e metodologia enunciados.

\subsection{Perfil da amostra}

Foi observado neste estudo um maior predomínio de enoturistas do gênero feminino, tanto no VV quanto no VSF (Tabela 1). A maior diferença entre gênero foi encontrada no VSF, onde o público feminino foi $15,6 \%$ maior que o masculino, enquanto que no VV essa diferença foi quase inexistente (2,8\%).

Esta predominância também é referida em outras pesquisas sobre o perfil do enoturista, especialmente em regiões ditas do novo mundo (Treloar, Hall e Mitchell 2004). Na Austrália, Pratt (2014) afirma que 53\% dos enoturistas inquiridos eram do sexo feminino, enquanto que em Charters e Ali-Knight (2002) os resultados chegaram a $54 \%$.

A média de idade do enoturista do VV foi de 39,4 anos. No VSF, a média de idade foi de 34,7 anos. Considerando-se as idades em faixa etárias (Tabela 1), o VV apresenta maior predominância de indivíduos entre 26 e 35 anos (32,2\%), seguidos da faixa entre 36 e 45 anos (23,0\%). No VSF, as duas faixas etárias principais foram entre 18 e 25 anos (35,4\%) e 26 a 35 anos (23,4\%). Esse resultado evidencia diferenças na representação etária dos enoturistas destes destinos. 
Tabela 1 - Caraterísticas socioeconómicas dos respondentes

\begin{tabular}{|c|c|c|c|c|}
\hline \multirow[b]{2}{*}{ Gênero } & \multicolumn{2}{|c|}{ Vale dos Vinhedos } & \multicolumn{2}{|c|}{ Vale do São Francisco } \\
\hline & $\mathbf{N}$ & $\%$ & $\mathbf{N}$ & $\%$ \\
\hline Feminino & 185 & 51,4 & 178 & 57,8 \\
\hline Masculino & 175 & 48,6 & 130 & 42,2 \\
\hline \multicolumn{5}{|l|}{ Faixas etárias de idade } \\
\hline 18 a 25 anos & 55 & 15,3 & 109 & 35,4 \\
\hline 26 a 35 anos & 116 & 32,2 & 72 & 23,4 \\
\hline 36 a 45 anos & 83 & 23,0 & 57 & 18,5 \\
\hline 46 a 60 anos & 74 & 20,6 & 55 & 17,8 \\
\hline Acima de 60 anos & 32 & 8,9 & 15 & 4,9 \\
\hline \multicolumn{5}{|l|}{ Estado Civil } \\
\hline Solteiro(a) & 102 & 28,3 & 157 & 51,0 \\
\hline Casado(a)/União Estável & 236 & 65,6 & 138 & 44,8 \\
\hline Divorciado(a) & 15 & 4,2 & 10 & 3,2 \\
\hline Viúvo(a) & 7 & 1,9 & 3 & 1,0 \\
\hline \multicolumn{5}{|l|}{ Escolaridade } \\
\hline Ensino Fundamental & 3 & 0,8 & 4 & 1,2 \\
\hline Ensino Médio & 31 & 8,6 & 47 & 15,3 \\
\hline Ensino Técnico & 17 & 4,7 & 72 & 23,4 \\
\hline Ensino Superior & 157 & 43,7 & 88 & 28,6 \\
\hline Pós Graduação & 152 & 42,2 & 97 & 31,5 \\
\hline \multicolumn{5}{|l|}{ Origem } \\
\hline Região Sul do Brasil & 199 & 55,3 & 2 & 0,6 \\
\hline Região Sudeste do Brasil & 129 & 35,8 & 49 & 15,9 \\
\hline $\begin{array}{l}\text { Região Centro-oeste do } \\
\text { Brasil }\end{array}$ & 14 & 3,9 & 6 & 1,9 \\
\hline Região Norte do Brasil & 3 & 0,8 & 0 & 0,0 \\
\hline Região Nordeste do Brasil & 6 & 1,7 & 247 & 80,2 \\
\hline Outras nacionalidades & 9 & 2,5 & 4 & 1,3 \\
\hline \multicolumn{5}{|l|}{ Faixas de renda } \\
\hline Até 1 salário & 15 & 4,2 & 94 & 30,5 \\
\hline Entre 1 e 3 salários & 53 & 14,7 & 56 & 18,2 \\
\hline Entre 3 e 7 salários & 90 & 25,0 & 50 & 16,2 \\
\hline Entre 7 e 10 salários & 76 & 21,1 & 39 & 12,7 \\
\hline Acima de 10 salários & 126 & 35,0 & 69 & 22,4 \\
\hline
\end{tabular}

Fonte: elaboração própria com base em inquérito aplicado aos turistas.

Os resultados encontrados por outros investigadores (por exemplo: Tassiopoulos, Nuntsu e Haydam 2004; O'Neil e Palmer 2004; O'Neill e Charters 2006) indicam, também, que os turistas que se deslocam a outras regiões vitivinícolas são, também, maioritariamente jovens. Em Alebaki e lakovidou (2010), por exemplo, cerca de 51\% dos enoturistas possuíam até 35 anos. Os dados recolhidos por Lameiras (2015) apontam no mesmo sentido.

Entretanto, estes resultados divergem dos obtidos em outras pesquisas, em que as faixas etárias dominantes abrangem pessoas com idades superiores, como, por exemplo, entre os 40 e os 60 anos (Tassiopoulos, Nuntsu e Haydam 2004; Getz e Brown 2006), entre 45 e 65 anos (Pratt 2011), entre 30 e 60 anos (Dodd e Bigotte 1997) e entre os 30 e os 50 anos (Mitchell e Hall 2006). 
Quanto ao estado civil, 65,6\% dos enoturistas que visitam as vinícolas do VV eram casados ou viviam em união estável e $28,3 \%$ eram solteiros (Tabela1). No VSF, os casados ou com união estável representaram $44,8 \%$ e os solteiros representaram $51 \%$.

A predominância de visitantes casados é mencionada por diversos autores (Tassiopoulos, Nuntsu, e Haydam 2004; Yuan et al. 2005; Alebaki e lakovodou 2010; Cordeiro, Mattos e Losso 2015). Em Costa (2008), por exemplo, 69,4\% dos inquiridos eram casados. Já em Lameiras (2015) e Pratt (2014) a proporção foi ainda maior: 67\% e $72,5 \%$, respetivamente.

No VV, 85,9\% possuíam pelo menos alguma formação acadêmica, enquanto que no VSF os enoturistas com ensino técnico representaram $23,4 \%$, os com ensino superior representaram $28,6 \%$ e os com pós-graduação representaram 31,5\%.

Resultados como estes são referidos em boa parte das investigações, tanto em países europeus com extensa tradição na produção vinho, como França, Itália, Portugal e Espanha, como em países com fabricação mais recente, como África do Sul, Austrália, Canadá e Estados Unidos (Turismo de Portugal 2006; Galloway et al. 2008; Alebaki e lakovodou 2010; Dodd e Bigotte 1997; Tassiopoulos, Nuntsu e Haydam 2004; Sparks 2007; Houghton 2008).

Em pesquisa realizada no Planalto Catarinense, região vitivinícola brasileira, Cordeiro, Mattos e Losso (2015) mencionam que 68\% dos inquiridos possuíam ensino superior ou pós-graduação.

Em relação à origem dos visitantes das vinícolas do $\mathrm{VV}, 55,3 \%$ eram da região sul do Brasil e 35,8\% da região sudeste. No VSF, $80,2 \%$ eram da região nordeste e $15,9 \%$ da região sudeste. Como era esperado, ambos os vales foram predominantemente visitados por indivíduos da região onde se inserem. Visitantes provenientes do estrangeiro foram encontrados em número bastante reduzido: $2,5 \%$ no VV e $1,3 \%$ no VSF.

Mitchell, Hall e Mcintosh (2002) e Mitchell e Hall (2006) mencionam que, usualmente, uma parte significativa dos visitantes residem próximo do local da vinícola. Além disso, as pesquisas nos levam a crer que a maior parte dos turistas de vinho são de origem nacional (Treloar, Hall e Mitchell 2004; Alebaki e lakovodou 2010; Charters e Ali-Knight 2002).

A faixa de rendimento dos inquiridos do $\mathrm{VV}$ de maior frequência (Tabela 1) foi a dos com mais de 10 salários mínimos (35,0\%), seguida dos com 3 e 7 salários mínimos (25,0\%). No VSF, a faixa mais frequente foi a dos com até 1 salário (30,5\%), seguida dos com renda acima de 10 salários mínimos (18,2\%).

No que se refere a rendimento, os resultados obtidos no VV são semelhantes àqueles encontrados por vários pesquisadores. Dodd e Bigotte (1997), por exemplo, salientam que os enoturistas costumam ser detentores de rendimento e nível educacional maiores que os encontrados em grupos de turistas, em geral. Entretanto, no VSF os resultados são menos perentórios nessa vertente.

\subsection{Consumo, interesse pelo vinho e conhecimento}

Os indivíduos que se consideram apreciadores ou consumidores de vinho representam $84,4 \%$ dos enoturistas do VV. Destes, a maioria $(56,8 \%)$ relata o consumo frequente, isto é, no mínimo uma vez na semana, e $12,6 \%$ muito frequente 
ou diário. No VSF, $74,4 \%$ dos enoturistas consideram-se apreciadores ou consumidores de vinho. Destes, $43,2 \%$ consomem frequentemente e 9,6\% muito frequentemente.

Numa investigação realizada na Grécia, Alebaki e lakovidou (2010) questionaram se, em geral, os inquiridos consumiam vinho. As análises sugeriram que $18,8 \%$ dos respondentes 'bebem muito vinho', $58,6 \%$ consomem 'o suficiente', 21,1\% 'bebem pouco' e 2,3\% não bebem vinho.

Perguntou-se também se participam em alguma associação ou confraria de vinhos. As respostas obtidas mostraram que apenas $11,4 \%$ dos enoturistas do W e $7,8 \%$ dos enoturistas do VSF dizem participar nessas associações ou confrarias.

Já na pesquisa realizada por Cordeiro, Mattos e Losso (2015), a relação dos enoturistas do planalto catarinense com o vinho caraterizou-se da seguinte maneira: cerca de $80 \%$ bebe vinho, destes, $27 \%$ uma e $20 \%$ duas vez por semana.

Quanto ao interesse sobre vinhos, a maioria (70,3\%) dos enoturistas do VV consideraram-se "interessados mas não conhecedores" e 24,6\% consideraram-se “interessados e conhecedores". No VSF, os resultados foram 68,1\% e $21,8 \%$, respetivamente, para as categorias em causa.

Em relação ao seu grau de conhecimento sobre vinhos, observou-se maiores percentuais entre os que classificaram seu conhecimento como fraco $(45,8 \%$ no VV e $44,1 \%$ VSF), seguidos de 31,7\% e 33,8\% com conhecimento médio, respetivamente.

A investigação de Alebaki e lakovidou (2010) sugere que 55,6\% consideram-se detentores de conhecimentos intermédios, seguidos dos altamente conhecedores (21,8\%). Charters e Ali-Knight (2002), em pesquisa similar, encontraram as taxas seguintes: $3,3 \%$ afirmaram ser altamente conhecedores; $37,4 \%$ conhecedores; $49,6 \%$ disseram possuir conhecimento limitado; e $9,7 \%$ indicaram não ter nenhum conhecimento.

\subsection{Perfís dos enoturistas do Vale dos Vinhendos e do Vale de São Franciso}

Para a realização de uma análise mais detalhada sobre o perfil dos visitantes fez-se necessário realizar cruzamentos entre variáveis. Para o efeito, optou-se por realizar uma análise de correspondência múltipla. Entretanto, no quadro desta comunicação, somente foram utilizadas as variáveis que apresentaram associação significativa, ao nível de $5 \%$.

Podendo equacionar-se executar a análise tomando por referências variáveis como a frequência de consumo de vinhos, visita recente a outra empresa vitivinícola ou grau de conhecimento sobre vinhos, por exemplo, optou-se por apresentar aqui os resultados obtidos usando a variável frequência de consumo de vinho. Os resultados em questão serão apresentados a seguir, divididos por região.

\section{i) Vale de São Francisco}

Com assinalado, o bloco de análise de correspondência múltipla que se apresenta a seguir tem como base a variável frequência de consumo de vinho, e dá origem a grupos distintos, conforme mostra a Figura 2.

O primeiro grupo reporta-se aos visitantes que não consomem vinho ou que o fazem com pouca frequência, não participam em confrarias ou associações de vinho, dizem-se não interessados no tema e classificam o seu conhecimento sobre 
vinho como nulo ou fraco. O segundo grupo é composto por visitantes que afirmam consumir vinho com pouco frequência, não participam em confrarias ou associações de vinho, dizem-se "interessados mas não conhecedores" e afirmam possuir conhecimento médio, nulo ou fraco sobre a problemática.

$\mathrm{Na}$ sequência, foram agrupados os visitantes que consomem vinho com frequência, não participam em confrarias ou associações de vinhos, se auto classificaram como "interessados, mas não conhecedores", e disseram ter conhecimento médio, nulo ou fraco sobre o tema.

O quarto grupo diz respeito aos visitantes que afirmaram consumir vinho frequentemente ou muito frequentemente, que participam em associações ou confrarias de vinhos, se dizem "interessados e conhecedores" ou ainda "interessados, mas não conhecedores". Além disso, classificam seu conhecimento como médio, bom ou muito bom.

Figura 2 - Análise de correspondência múltipla com base na variável frequência de consumo de vinho (VSF)

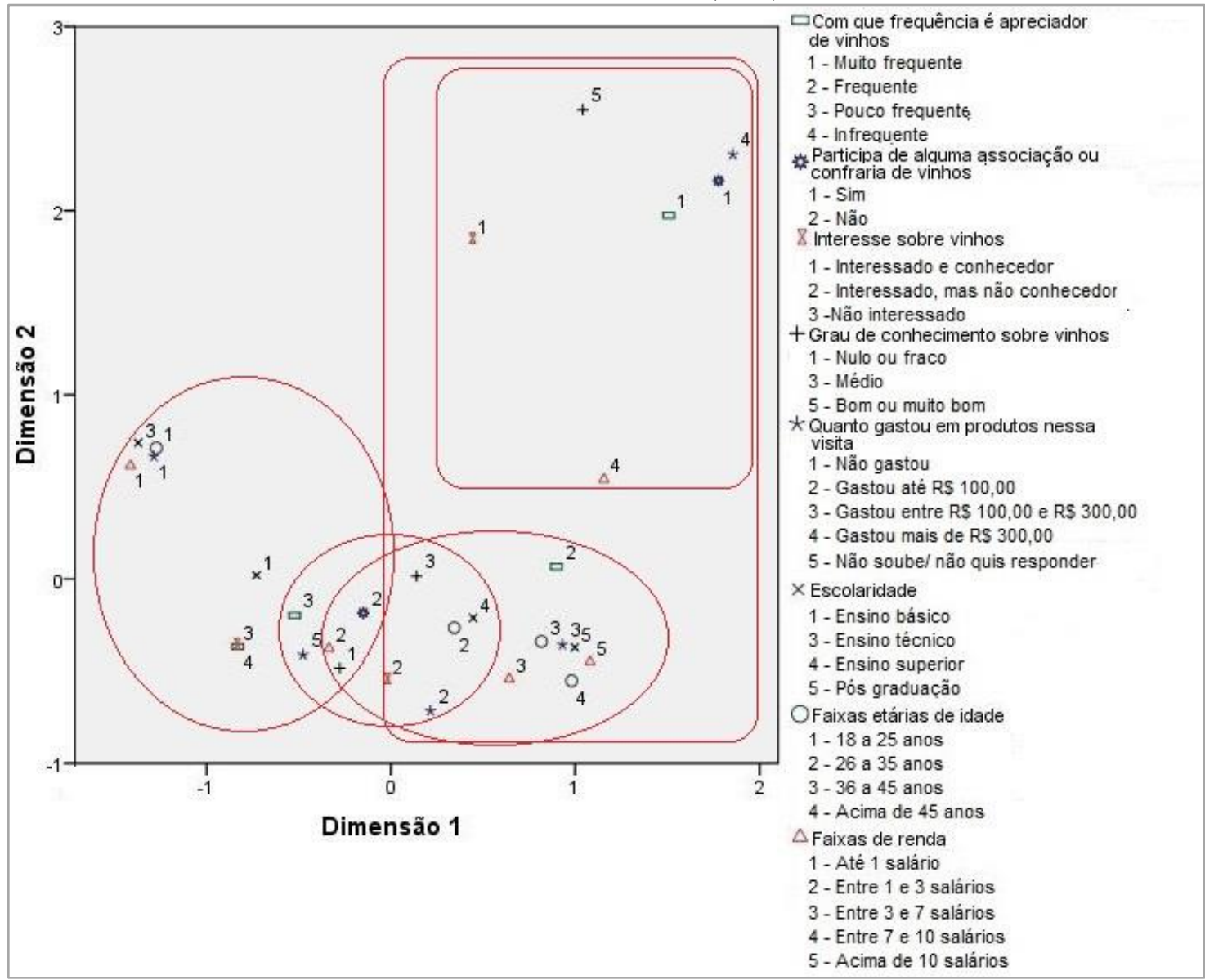

Fonte: elaboração própria com base em inquérito aplicado aos turistas.

ii) Vale dos Vinhedos

Consoante o realizado para a região vitivinícola do VSF, far-se-á também a análise de correspondência múltipla dos grupos do $\mathrm{VV}$ tomando como base a variável frequência de consumo de vinho (Figura 3). 
O primeiro bloco é formado por visitantes que afirmaram consumir vinho com muita frequência, que participam em confrarias ou associações de vinho, se dizem "interessados e conhecedores" sobre vinhos e possuem conhecimento bom ou muito bom.

Figura 3 - Análise de correspondência múltipla com base na variável frequência de consumo de vinhos (V)

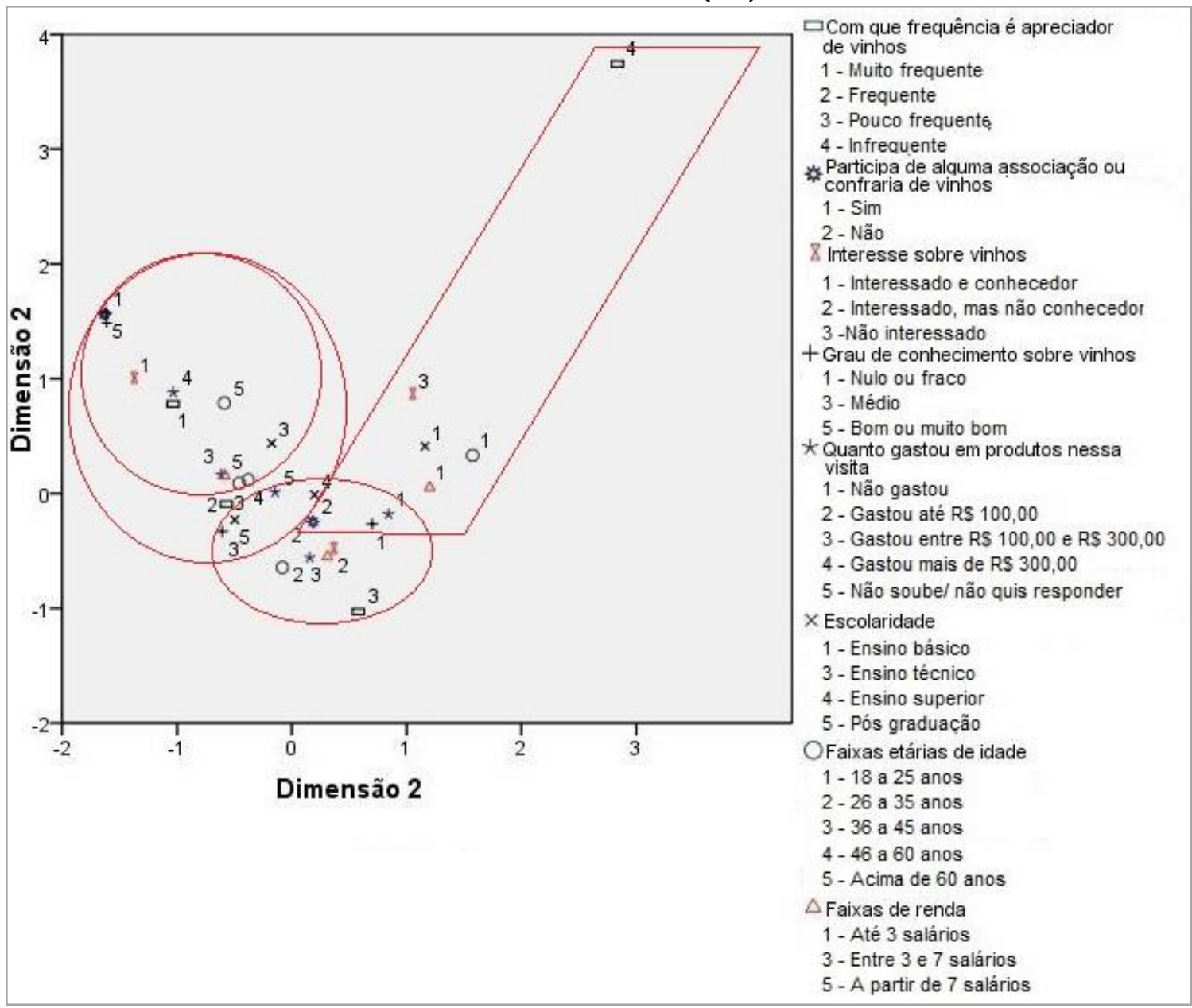

Fonte: elaboração própria com base em inquérito aplicado aos turistas.

O segundo grupo contempla aqueles que disseram consumir vinho frequentemente, que participam em associações ou confrarias de vinhos, têm idade superior a 35 anos, e classificam-se como "interessados e conhecedores", detentores de conhecimento médio, bom ou muito bom sobre vinhos.

O terceiro grupo diz respeito aos visitantes que afirmam consumir vinho com pouca frequência, não participam em confrarias ou associações de vinhos, alegam ser "interessados, mas não conhecedores", com conhecimento nulo, fraco ou médio sobre vinhos.

O quarto grupo contempla aqueles que não consomem vinho, não participam em associações ou confrarias de vinhos, não se interessam pelo tema e classificam seu conhecimento como nulo ou fraco.

ii) Perfil dos enoturistas 
Realizadas as análises anteriores, podemos dizer que, em ambas as regiões vitivinícolas brasileiras, de maneira geral, encontraram-se quatro diferentes grupos, tal qual se sugeriu nos dados acima apresentados. As variáveis relacionadas com o vinho foram fundamentais para a distribuição entre as categorias que se propõem abaixo. Em sua essência, apresentaram caraterísticas muito similares no VV e VSF, conforme se exporá a seguir.

Apaixonados: são visitantes que pertencem ao grupo mais focado no vinho, dizem-se interessados e possuem altos níveis de conhecimento sobre o tema, consomem vinho com bastante frequência, participam em associações ou confrarias de vinho, costumam gastar mais em produtos que as outras categorias de visitantes e, muito provavelmente, visitaram outras empresas vitivinícolas recentemente. No Vale dos Vinhedos, também foi possível inferir que costumam ser indivíduos com rendimento bem acima da média (geralmente superior a 10 salários mínimos) e idade superior a 35 anos.

Interessados: os turistas pertencentes a este grupo também apresentam bons conhecimentos sobre o tema, têm idade superior a 25 anos e se dizem "interessados e conhecedores" ou "interessados, mas não conhecedores". Entretanto, o seu grau de conhecimento sobre vinhos é usualmente inferior ao de um "apaixonado". Também costumam participar em confrarias ou associações de vinho, afirmam ter visitado outra vinícola recentemente, compram produtos na loja da empresa vitivinícola, mas o seu gasto é intermédio, normalmente inferior $\mathrm{R} \$ 300,00$. Os dados obtidos mostram-nos que no Vale do São Francisco este grupo compreende indivíduos com altos níveis educacionais e rendimento médio. Já no Vale dos Vinhedos tendem a ser homens, com rendimentos médio-altos e que consomem vinho com muita frequência.

Visitantes Ocasionais: este grupo de enoturistas contempla aqueles visitantes que se interessam pelo tema mas não detêm maiores conhecimentos sobre o assunto, se dizem "interessados, mas não conhecedores" e classificam o seu conhecimento como nulo ou fraco (pontualmente, médio). São indivíduos que não participam em confrarias ou associações de vinho, não visitaram outra empresa vitivinícola recentemente, mas disfrutam da experiência e compram produtos na loja da empresa vitivinícola. Ainda assim, o seu gasto é baixo, geralmente inferior à $\mathrm{R} \$ 100,00$. No Vale dos Vinhedos, pôde-se observar que este agrupamento tende a ser composto por mulheres com rendimento variável, frequentemente inferior a 10 salários mínimos.

Indiferentes: este grupo compreende aqueles visitantes que muito provavelmente não visitaram a região em função dos vinhos ou de atividades ligadas a estes, não se interessam pelo tema e classificam o seu conhecimento como nulo ou fraco, bebem vinho com pouca ou nenhuma frequência e, geralmente, não gastam nada ou quase nada em produtos nas empresas vitivinícolas. São indivíduos jovens: no Vale do São Francisco, tendem a ter idade inferior a 25 anos; e, no Vale dos Vinhedos, tendem a ter idade inferior a 35 anos. No que se refere a rendimento, costumam ter renda baixa e média-baixa, por referência às respetivas regiões de origem.

Ao comparar-se os resultados obtidos nesta investigação com aqueles encontrados noutros estudos similares referidos na seção de revisão de literatura, podem realizar-se algumas considerações sobre o tema. O número de clusters 
utilizado por diversos autores, por exemplo, também costuma gerar quatro grupos distintos (conferir: Corigliano 1996; Charters e Ali-Knight 2002; Brown, Havitz e Getz 2006); Alebaki e lakovidou 2010; Lameiras 2015).

Como assinalado, Charters e Ali-Knight (2002), em estudo realizado na Austrália, dividem os enoturistas em: wine lover, the conosseur, wine interested e wine novice. Apesar de algumas diferenças, pode dizer-se que os wine lovers se aproximam daqueles que denominamos "apaixonados", visto que representam um grupo mais focado no vinho e que tem níveis superiores de conhecimento sobre o tema. O mesmo ocorre com os wine interested, que é, inclusive, denominado por nós de forma parecida ("interessados"), representando um grupo que tem conhecimento intermédio sobre a temática do vinho e alguma experiência anterior no assunto.

Alebaki e lakovidou (2010), por sua vez, denominaram os agrupamentos de: wine lovers; the neophytes; ocasional visitors; e hangers-on. Este último é o que mais se aproxima da categoria que designámos por "indiferentes", visto que são visitantes que não se interessam pelo vinho. Em geral, também não consomem este produto e têm baixo ou nenhum conhecimento sobre vinhos. No que se refere aos ocasional tourists, os autores (Alebaki \& lakovidou, 2010) afirmam que são indivíduos motivados para visitar a região do vinho principalmente em função da gastronomia local, e que boa parte deles não está interessada em desenvolver os seus conhecimentos sobre vinho.

Desta forma, podemos dizer que, apesar de terem uma denominação parecida à dos "visitantes ocasionais", estes grupos divergem essencialmente nas suas caraterísticas, visto que os encontrados em VSF e VV têm interesse na temática do vinho, mesmo que de forma limitada. Também não se pode afirmar com precisão se este grupo tem ou não interesse na gastronomia local.

É interessante notar que é possível realizar um paralelo com a pesquisa realizada por Marzo-Navarro e Pedraja-Iglesias (2009), que dividiram os enoturistas em dois grupos distintos, o primeiro deles denominado de wine interesteds, em sua maioria do sexo masculino, que bebem vinho com frequência e possuem mais conhecimento, interesse e envolvimento com o vinho, e o segundo, chamado de wine curious, composto maioritariamente por mulheres que bebem vinho com pouca frequência.

Pode-se então dizer-se que os grupos "interessados" e "visitantes ocasionais" encontrados na região do VV se aproximam daqueles encontrados em Espanha por Marzo-Navarro e Pedraja-Iglesias (2009), ao referirem-se, respetivamente, a homens que têm mais conhecimento sobre e que consomem vinho com maior frequência, e mulheres com menor interesse e conhecimento sobre o tema.

\section{Conclusão}

A revisão de literatura tornou possível refletir sobre o tema proposto (o nosso objetivo prinicipal era traçar o perfil dos enoturistas dos Vales dos Vinhedos e de São Francisco) e, e contituiu ponto de partida para a aproximação empírica desenvolvida nesta investigação. Num primeiro momento, fez-se menção ao enoturismo e aos conceitos com ele relacionados, fez-se referência às intersecções 
deste com outros tipos de turismo, aos atrativos turístico, ao produto turístico e à procura enoturística, em geral. Nesse contexto, também se disse que o conceito de enoturismo segue em fase de construção, e, mesmo que tenha recebido contribuições de um número elevado de autores, as abordagens têm sido distintas e os resultados encontrados nem sempre têm sido convergentes.

Também se constatou que é necessário que se façam maiores esforços para compreender de maneira mais profunda as necessidades e expectativas do visitante, visto que este leva consigo crenças sobre o local e sobre a experiência do enoturismo, advindas de uma diversa gama de fontes de informação. O visitante espera ter uma experiência autêntica, que depende do esforço conjunto das indústrias do vinho e do turismo, nomeadamente no que se refere a perfís dos enoturistas.

Quanto às propostas de segmentação propostas, foi interessante notar que, da mesma forma que o conceito de enoturismo se foi modificando ao longo dos anos, a dificuldade de definir o enoturista tornou-se crescente. Para caraterizar o enoturista, para além de variáveis demográficas, psicográficas, ou de ambas, o conhecimento do visitante sobre vinhos tem sido usado com frequência como indicador de referência, dando origem a distintas propostas de segmentação.

Estudos deste tipo têm sido realizados por autores de países quer do velho quer do novo mundo vitivinícolas, isto é, com ou sem tradição na fabricação de vinhos, algo que também acrescenta complexidade aos retratos que podem ser traçados.

Pegando nos casos do Vale do São Francisco e do Vale dos Vinhedos, no Brasil, e recorreendo a uma série de tratamentos estatísticos, que culminaram num conjunto de análises de correspondência múltipla, utilizando as variáveis que apresentaram associação significativa, chegou-se a uma proposta de agrupamento geral dos enoturistas. Estes, foram denominados: apaixonados; interessados; visitantes ocasionais; e indiferentes. Sendo esta uma tipologia agregadora dos vistitantes-tipo das duas regiões brasileiras objeto de investigação, cumprirá que se sublinhe que à particularidades entre elas.

Os Apaixonados são visitantes que pertencem ao grupo mais focado no vinho, propriamente dito, dizem-se interessados e possuem altos níveis de conhecimento sobre vinhos, consomem vinho com bastante frequência, participam em associações ou confrarias de vinho, costumam gastar mais em produtos que as outras categorias de visitantes e, muito provavelmente, visitaram outras empresas vitivinícolas recentemente. No Vale dos Vinhedos, também foi possível concluir que costumam ser indivíduos com renda bem acima da média e idade superior a 35 anos.

No que aos Interessados se refere, os dados obtidos mostram que, no Vale do São Francisco, este grupo compreende indivíduos com altos níveis educacionais e renda média. Já no Vale dos Vinhedos tendem a ser homens, com rendimentos médio-altos e que consomem vinho com muita frequência. No respeitante aos Visitantes Ocasionais, no Vale dos Vinhedos pôde observar-se que este agrupamento tende a ser composto por mulheres com rendimento variável, frequentemente inferior a 10 salários mínimos. No Vale do São Francisco, os Indiferentes são indivíduos jovens (tendem a ter idade inferior a 25 anos), enquanto que no Vale dos Vinhedos tendem a ser indivíduos com idade inferior a 35 anos. No que se refere a 
renda, em ambos os casos tendem ter renda baixa e média-baixa por referência à realidade das respetivas regiões.

Acredita-se que estes resultados possam contribuir para uma maior compreensão sobre quem são os enoturistas. Através deles, os empreendimentos de enoturismo poderão ser capazes de implementar estratégias de marketing melhor endereçadas aos públicos-alvo, e, também, ajustarem a respetiva oferta em matéria de serviço/produtos e, por essa via, tornarem-se mais competitivos. Isso tem particular cabimento no Brasil onde o enoturismo se encontra, ainda, em fase de estruturação e desenvolvimento.

A concluir, é importante mencionar as limitações encontradas na realização desta investigação, desde logo, para assinalar a dificuldade de obter apoio das unidades vitivinícolas, visto que algumas destas não se mostraram favoráveis à recolha in loco dos dados. Importa também ter presente os custos consideráveis de estadia e deslocação para a aplicação dos questionários, que não permitiram tirar pleno partido do potencial de dados que poderiam ser recolhidos no trabalho de campo. Adicionalmente, importa fazer presente que os dados que aqui se reportam constituem uma exploração parcial da base dados construída, tendo sido posta a ênfase na componente quantitativa, e mesmo esta é explorada muito parcialmente. Razões de extensão do artigo ditaram a opção se que fez.

Em investigações futuras, poderá justificar-se recorrer à estimação de modelos de regressão logística para identificar o tipo de relações entre algumas variáveis ou conjuntos destas, e analisar outras regiões vitivinícolas do país, de modo a construir um modelo de pesquisa que possa ter uma representatividade nacional inequívoca.

\section{REFERÊNCIAS}

AENOTUR. Associação Internacional do Enoturismo. 2018. Disponível em: <http://www.aenotur.com>. Acesso em: 21 mar. 2018.

ALANT, K. e BRUWER, J. Wine tourism behaviour in the context of motivational framework for wine regions and cellar doors. Journal of Wine Research 15(1), p. 2737, 2004.

ALEBAKI, M. e IAKOVODOU, O. Segmenting the Greek Wine Tourism Market using a Motivational Approach. New Medit 9(4), p. 31-40, 2010.

APROVALE. Vale dos Vinhedos - Associação dos Produtores de Vinhos Finos do Vale dos Vinhedos. 2018. Disponível em: <http://www.valedosvinhedos.com.br/>. Acesso em: 21 mar. 2018.

ATOUT France. Tourisme et Vin. Paris : Atout France, 2010.

BENI, M. Turismo: da economia de serviços à economia da experiência. Turismo: Visão e Acção 6(3), p. 294-305, 2004. 
BROWN, G., HAVITZ, M. e GETZ, D. Relationship between wine involvement and wine related travel. Journal of Travel \& Tourism Marketing 21(1), p. 31-46, 2006.

BRUWER, J., LI, E. e REID, M. Segmentation of the Australian Wine Market Using a Wine-Related Lifestyle Approach. Journal of Wine Research 13(3), p. 217-242. 2002.

CAMBOURNE, B. e MACIONIS, N. Meeting the wine-maker: wine tourism product development in an emerging wine region. HALL, M.; SHARPLES, L.; CAMBOURNE, B.; MACIONIS, N. (Eds.). Wine Tourism Around the World: Development, Management and Markets. Butterworth-Heinemann, Oxford, pp. 81-101, 2002.

CAMBOURNE, B., MACIONIS, N., HALL, M. e SHARPLES, L. The future of wine tourism. In: HALL, M.; SHARPLES, L.; CAMBOURNE, B.; MACIONIS, N. (Eds.). Wine tourism around the world: Development, management and markets. ButterworthHeinemann, Oxford, p. 297-320, 2002.

CHATERS, S. e ALI-KNGHT, J. Who is the wine tourist? Tourism Management 23, pp. 311-319, 2002.

CORDEIRO, W., MATTO, J. e LOSSO, F. A vitivinicultura de altitude em Santa Catarina (Brasil): espaços privilegiados para o turismo. Turismo \& Sociedade 7(3), p. 418-445, 2015.

COSTA, A. e KASTENHOLZ, E. O enoturismo como fator de desenvolvimento das regiões mais desfavorecidas. CONGRESSO DE DESENVOLVIMENTO REGIONAL DE CABO VERDE, 1, 2009 / CONGRESSO DA APDR, 15, 2009, Coimbra. Atas... Coimbra: APDR, p. 1489-1508, 2009.

COSTA, P. Análise do perfil do enoturista da região demarcada do Dão. 2008. Dissertação (Mestrado em Gestão e Desenvolvimento em Turismo) - Universidade de Aveiro, Aveiro, 2008.

DANCAL, J. e GONZAGA, S. RS: Economia e Política. Porto Alegre Mercado Aberto, 1979.

DELOITTE VINTUR PROJECT. European Enotourism Handbook. Project VINTUR, Deloitte, 2005.

DODD, T. e BIGOTTE, V. Perceptual differences among visitor groups to wineries. Journal of Travel Research 27(Winter), p. 46-51, 1997.

FALCADE, I. Paisagens vitícolas brasileiras. X Congresso Brasileiro de Viticultura e Enologia. Bento Gonçalves, 2005.

FLORES, M. A. e FLORES, A. Diagnóstico do enoturismo brasileiro: um mercado de oportunidades. IBRAVIN, SEBRAE, Brasília, 2012. 
GALLOWAY, G., MITCHELL, R., GETZ, D., CROUGH, G. e ONG, B. Sensation seeking and the prediction of attitudes and behaviours of wine tourists. Tourism Management 29(5), p. 960-966, 2008.

GALVÃO, P. Enoturismo e dinâmica sócio-espacial no Vale do São Francisco (PE). 2009. Dissertação (Mestrado em Geografia) - Universidade Federal de Pernambuco, Recife, 2009.

GATTI, S. e MARONI, F. A Profile of Wine Tourist in some Italian region wineyards: an applicattion of the multiple correspondence analysis. Vineyard Data Qualification Society (VDQS) Colloque. OEnometrics XI, Dijon, 2004.

GETZ, D. Wine tourism: global overview and perspectives on its development. In: CARLSEN, J.; DOWLING, R. (Eds.). Wine Tourism: Perfect Partners. Proceedings of the First Australian Wine Tourism Conference. First Australian Wine Tourism Conference, Margaret River, 1998.

GETZ, D. Wine Tourism, Management, Development \& Destinations. Washington: Library of Congress Cataloging, 2000.

GETZ, D. \& BROWN, G. Critical success factors for wine tourism regions: a demand Analysis. Tourism Management 27(1), p.146-158, 2006.

HALL, C., JOHNSON, G., CAMBOURNE, B., MACIONIS, N., MITCHELL, R. e SHARPLES, L. Wine tourist: an introduction. In: HALL, M.; SHARPLES, L.; CAMBOURNE, B.; MACIONIS, N. (Eds.). Wine Tourism Around the World: Development, Management and Markets. Oxford: Butterworth-Heinemann, p. 1-23, 2002.

HALL, M. e MACIONIS, N. Wine tourism in Australia and New Zealand. In: BUTLER, R.; HALL, M.; JENKINS, J. (Eds.). Tourism and Recreation in Rural Areas. Chichester, John Wiley \& Sons, Chichester, p. 197-224, 1998.

HOUGHTON, M. Classifying wine festival customers: Comparing an inductive typology with Hall's wine tourist classification. International Journal of Culture, Tourism and Hospitality Research 2(1), pp. 67-76, 2008.

INÁCIO, A. Enoturismo: da tradição à inovação, uma forma de desenvolvimento rural. In: CONGRESSO DE ESTUDOS RURAIS, 3, 2008, Faro. Atas... Faro: Universidade do Algarve - SPER/Ualg, 2008.

JOHNSON, G. Wine tourism in New Zealand: A national survey of wineries 1997. (Diploma in Tourism Dissertation) - University of Otago, Otago, 1998.

LAMEIRAS, E. O perfil do enoturista- o caso português. Tese (Doutoramento em Turismo) - Universidade do Algarve, Faro, 2015. 
LEWIS, R. e CHAMBRES, R. Marketing Leadership in Hospitality. Van Nostrand Reinhold, New York, 1989.

LOCKS, E. e TONINI, H. Enoturismo: o vinho como produto turístico. Turismo em Análise 16(2), p. 157-173, 2005.

LOPEZ-GUZMÁN, T., VÁZQUEZ, G., CARIDAD, G. e OCERÍN, J. Análisis econométrico del enoturismo en España: un estudio de caso. Estudios y Perspectivas en Turismo 17, p. 98-118, 2008.

MANCINO, A. e LO PRESTI, O. Wine tourism: a business opportunity for winemakers. International Journal of Business and Globalisation 8(1), p.153-169, 2012.

MARZO-NAVARRO, M. e PEDRAJA-IGLESIAS, M. Profile of a wine tourist and the correspondence between destination and prefered wine. A study in Aragon, Spain. Journal of Travel \& Tourism Marketing 26(7), p. 670-687, 2009.

MCKINA, D. 1987. Developing Marketing Strategies for Wines. In: HAYES, P. (Ed.), Proceedings of the Grapes and Wine -The Business End Conference. Victorian Wine Industry Association, Melborne, 18-19 August, 1987.

MITCHELL, R. e HALL, M. Wine tourism research: the state of play. Tourism Review International 9(4), p. 307-332, 2006.

MITCHELL, R. e HALL, C. e MCINTOSH, A. Wine tourism and consumer behavior. In: HALL, C.; SHARPLES, L.; CAMBOURNE, B.; MACIONIS, N. (Eds). Wine tourism around the world: development, management and markets. Oxford: Elsevier, p. 115$135,2002$.

NOVAIS, C. e ANTUES, J. O contributo do Enoturismo para o desenvolvimento regional: o caso das Rotas dos Vinhos. In: CONGRESSO DE DESENVOLVIMENTO REGIONAL DE CABO VERDE, 1, 2009 / CONGRESSO DA APDR, 15, 2009, Coimbra. Atas..., Coimbra: APDR, p. 1253-1280, 2009.

O'NEILL, M. e CHATERS, S. Survey Timing and Visitor Perceptions of Cellar Door Quality. In: CARLSEN, J.; CHARTERS, S. (Eds.). Global Wine Tourism: Research, Management and Marketing. CAB International, Cambridge, p. 161-176, 2006.

O'NEILL, M. e PALMER, A. Wine production and tourism: Adding service to a perfect partnership. Cornell Hotel and Restaurant Administration Quarterly, 45(3), p. 269284, 2004.

O'NEILL, M. e CHATERS, S. Service quality at the cellar door: implications for Western Australia's developing wine tourism industry. Managing Service Quality 10(2), p. 112-22, 2000.

PANOSSO, A. Filosofia do Turismo: Teoria e Epistemologia. São Paulo: Aleph, 2005. 
PETER, J. e OLSON, J. Consumer behaviour and marketing strategy. MCGrawHill/Irwin Series in Marketing, 2001.

PRATT, M. Profiling wine tourists, more than just demographics. In: 6TH AWBR INTERNATIONAL CONFERENCE, 6, 2011, Bordeaux. Bordeaux Management School, Bordeaux, 9-10 June, 2011.

PRATT, M. Four Wine Tourists Profiles. In: INTERNATIONAL CONFERENCE, 8, 2014, Geisenheim. Academy of Wine Business Research, Geisenheim, 28-30 June, 2014.

REYES, C. 2012. The Satisfaction of Wine Tourist: Causes and Effects. European Journal of Tourism Research 5(1), p. 80-83, 2012, 2012.

SERENHO, M. e ÁGUAS, P. Perfil do Enoturista. Revista da ESGHT-UAlg 15, p. 21-30, 2006.

SPARKS, B. Planning a wine tourism vacation? Factors that help to predict tourist behavioural intentions. Tourism Managment 28(5), p. 1180 -1192, 2007.

SPAWTON, T. Understanding wine purchasing: knowing how the wine buyer behaves can increase sales. The Australian and New Zealand Wine Industry Journal 1(2), p. 54-57, 1986.

TASSIOPOULOS, D. e HAYDAM, N. Wine Tourist in South Africa: a demand-side Study. J. Carlsen e S. Charters (Eds.). Global Wine Tourism: Research, Management and Marketing. CAB International, Cambridge, p. 141-152, 2006.

TASSIOPOULOS, D., NUNTSU, N. e HAYDAM, N. 2004. Wine Tourists in South Africa: A Demographic and Psychographic Study. Journal of Wine Research, 15(1), p. 51-63, 2004.

TAYLOR, R. Wine Festivals and Tourism: Developing a Longitudinal Approach to Festival Evolution. J. Carlsen e S. Charters (Eds.). Global Wine Tourism: Research, Management and Marketing. CAB International, Cambridge, p. 179-195, 2006.

TRELOAR, P., HALL, M. e MITCHELL, R. Wine Tourism and the generation Y market: any possibilities? CAUTHE 2004: Creating Tourism Knowledge. CAUTHE 2004 Conference, Brisbane, Queensland, 2004.

TURISMO DE PORTUGAL. PENT - Plano Estratégico Nacional do Turismo. Turismo de Portugal, Lisboa, 2006.

VALDUGA, V. O Desenvolvimento do Enoturismo no Vale dos Vinhedos (RS/BRASIL). Cultur - Revista de Cultura e Turismo 6(2), p. 127-143, 2012. 
VARGAS, A., BUENO, N., MEJIA, M. e LIGERO, F. Turismo e Industria Vinícola, perspectivas y propuestas para su desarrollo en la província de Huelva. Servicio de Publicaciones - Universidad de Huelva, Huelva, 2008.

WILLIAMSD, P. e KELLY, J. Cultural wine tourists: product development considerations for British Columbia's resident wine tourism market. International Journal of Wine Marketing 13(3), p. 59-77, 2001.

WTTC. The Economic Impact of Travel \& Tourism. World Travel and Tourism Council, 2014.

YUAN, J., CAI, L., MORRISON, A. e LINTON, S. An analysis of wine festival attendees' motivations: a synergy of wine, travel and special events? Journal of Vacation Marketing 11(1), p. 41-58, 2005.

ZANINI, T. e ROCHA, J. O Enoturismo no Brasil: um estudo comparativo entre as regiões vinícolas do Vale dos Vinhedos (RS) e do Vale do São Francisco (BA/PE). Revista Turismo em Análise 21(1), p. 68-88, 2010.

Bárbara Dal Rosso Lima. Escola de Economia e Gestão, Universidade do Minho, Braga, Portugal. badalrosso@gmail.com

J. Cadima Ribeiro. NIPE e Escola de Economia e Gestão, Universidade do Minho, Braga, Portugal. jcadima@eeg.uminho.pt

Vinícius Pinheiro Nunes. Instituto de Matemática, Estatística e Física, Universidade Federal de Rio Grande, Rio Grande/RS, Brasil. vini.estatistica@gmail.com

Como citar: DAL ROSSO LIMA, Bárbara; RIBEIRO, José Cadima; NUNES, Vinícius Pinheiro. Enoturismo no Brasil: um estudo comparativo dos perfís dos enoturistas do Vale dos Vinhedos e do Vale de São Francisco. Redes (St. Cruz Sul, Online), Santa Cruz do Sul, v. 25, n. 2, p. 782-808, mar. 2020. ISSN 1982-6745. Disponível em: https://online.unisc.br/seer/index.php/redes/article/view/13521 Acesso em: 15 maio 2020. doi: https://doi.org/10.17058/redes.v25i2.13521 


\section{CONTRIBUIÇÃO DE CADA AUTOR}

i) Bárbara Dal Rosso Lima

Fundamentação teórico-conceitual e problematização; revisão da literatura; definição e apresentação da metodologia usada; pesquisa de dados e contribuição para a análise estatística; contribuição para a redação do texto; seleção das referências bibliográficas.

ii) J. Cadima Ribeiro

Contribuição para a fundamentação teórico-conceitual e problematização; contribuição para a revisão da literatura; contribuição para a definição e apresentação da metodologia; redação do texto; contribuição para a seleção das referências bibliográficas.

iii) Vinícius Pinheiro Nunes

Contribuição para a definição da metodologia usada; análise estatística; contribuição para a elaboração de figuras e tabelas. 